\title{
The prevalence, incidence and natural history of primary sclerosing cholangitis in an ethnically diverse population
}

\author{
Elaine Toy ${ }^{1}$, Sripriya Balasubramanian², Carlo Selmi ${ }^{3,4}$, Chin-Shang $\mathrm{Li}^{5}$ and Christopher $L$ Bowlus ${ }^{6 *}$
}

\begin{abstract}
Background: Primary sclerosing cholangitis (PSC) is a rare chronic cholestatic liver disease often associated with inflammatory bowel diseases (IBD). Current epidemiological data are limited to studies of predominantly Caucasian populations. Our aim was to define the epidemiology of PSC in a large, ethnically diverse US population.

Methods: The Northern California Kaiser Permanente (KP) database includes records from over 3 million people and was searched for cases of PSC between January 2000 and October 2006. All identified charts were reviewed for diagnosis confirmation, IBD co-morbidity, and major natural history endpoints.

Results: We identified 169 (101 males) cases fulfilling PSC diagnostic criteria with a mean age at diagnosis of 44 years (range 11-81). The age-adjusted point prevalence was 4.15 per 100,000 on December 31, 2005. The ageadjusted incidence per 100,000 person-years was not significantly greater in men 0.45 (95\% Cl 0.33 - 0.61) than women 0.37 (95\% Cl 0.26 - 0.51). IBD was present in 109/169 (64.5\%) cases and was significantly more frequent in men than women with PSC $(73.3 \%$ and $51.5 \%$, respectively, $\mathrm{p}=0.005)$. The cumulative average yearly mortality rate was $1.9 \%$. Age and serum sodium, creatinine and bilirubin at diagnosis and albumin at last entry were identified as significant factors associated with death, liver transplant or cholangiocarcinoma.
\end{abstract}

Conclusions: The incidence and prevalence of PSC observed in a representative Northern California population are lower compared to previous studies in Caucasian populations and this might reflect differences in the incidence of PSC among various ethnic groups.

Keywords: epidemiology, transplantation, cholangiocarcinoma, inflammatory bowel disease

\section{Background}

Primary sclerosing cholangitis (PSC) is a chronic cholestatic liver disease of unknown etiology [1] characterized by classic findings of multiple segmental strictures in the intra- and extra-hepatic bile ducts secondary to inflammation and obliterative fibrosis. Less common, the small duct PSC subtype is characterized by a normal cholangiogram and a better prognosis [2]. Inflammatory bowel disease (IBD) is found in $65-90 \%$ of PSC cases and though usually classified as ulcerative colitis (UC), the IBD associated with PSC has a unique phenotype including pancolitis, ileitis, rectal sparing and is often asymptomatic $[3,4]$.

\footnotetext{
* Correspondence: clbowlus@ucdavis.edu

${ }^{6}$ Division of Gastroenterology and Hepatology, University of California Davis Medical Center, Sacramento, CA USA

Full list of author information is available at the end of the article
}

Both environmental and genetic risk factors have been associated with PSC susceptibility, in some cases being common to the IBD background, as in the case of smoking [5-7]. Interestingly, the association of PSC with the human leukocyte antigen DR3-B8-A1 haplotype found in Northern European populations [8,9] has not been reproduced in Italian or Brazilian PSC cohorts suggesting that genetic risks for PSC may vary between populations $[10,11]$. In African-Americans patients listed for liver transplantation in the US, we have recently shown that PSC is associated with HLA-B8, but not HLA-DR3 suggesting a common genetic risk factor near the HLA-B locus [12].

The overall risk and clinical presentation of PSC also appears to vary between populations. Population-based studies in different geographical areas of primarily

\section{Biomed Central}


Northern European ancestry have demonstrated annual incidence rates ranging between 0.41 and 1.2 per 100,000 person-years [13-18]. In populations of Asia, Southern Europe and Alaska, the prevalence of PSC appears much lower and with a lower frequency of IBD [19-25]. In contrast, small case series suggested that IBD patients of African descent are at greater risk of PSC, [26,27] although this has not been recapitulated in a larger study [28]. Our own analysis of liver transplant registrants in the US identified African-American race as a significant risk factor for PSC patients even after controlling for socioeconomic and other factors [12]. The aim of the present study was to determine whether the ethnic differences identified in the liver transplant registrant population extends to PSC patients in general by measuring the incidence, prevalence, natural history, and IBD co-morbidity in a large health maintenance organization consisting of over 3 million subjects representing an ethnically diverse population.

\section{Methods}

\section{Study population}

We utilized the membership database of the northern California Kaiser-Permanente Medical Care Plan (KP). This is a prepaid health maintenance organization that provides medical care to approximately 25-30 percent of the population primarily located in urban areas of the greater San Francisco Bay and Sacramento metropolitan areas. Comparison of KP membership data and census data demonstrate that the KP membership is closely representative of the Northern California population in many demographic variables with the exception of small differences in education and income [29]. A random sample of 5,080, members in 2001 was comprised of $64 \%$ non-Hispanic white, 12\% Hispanic, 6\% AfricanAmerican, 16\% Asian and 3\% other [30]. According to 2000 US census data the population of the twelve counties served by KP was $51.1 \%$ non-Hispanic white, $19.8 \%$ Hispanic, 7.5\% African-American, 17.0\% Asian and 4.6\% other. The study was conducted with the approval of the Kaiser Foundation Research Institute Institutional Review Board.

\section{Case ascertainment}

After approval by the Institutional Review Board, the northern California KP database was searched for PSC diagnoses entered between January 2000 and October 2006. Unlike ICD-9 coding which does not allow for a specific code for PSC, the KP database utilizes a unique code for PSC. The charts of all subjects identified were then reviewed for biochemical, cholangiographic, and/or histological evidence of PSC. Inclusion criteria consisted of radiographic evidence of PSC on cholangiogram or histological evidence on liver biopsy. When neither test was positive for PSC the case was excluded from further analysis despite the PSC coding. Small duct PSC was defined as histological findings consistent with PSC and a normal cholangiogram. Exclusion criteria included secondary causes of biliary sclerosis. Natural history endpoints included liver transplant, cholangiocarcinoma, and death. Additional collected data included age, gender, date of diagnosis, laboratory studies at diagnosis, means of diagnosis, and the presence of IBD. Data on race and ethnicity were recorded when mentioned in the medical record but were available on less than half of the cases and were not included in this analysis.

\section{Statistical Analysis}

Age- and/or gender-adjusted rates and 95 percent confidence intervals were calculated using direct standardization with the age and/or gender distribution of the 2000 US population as the reference population. To compare the female and male groups for the (overall) ageadjusted incidence rates of PSC, we used the method of Dobson et al. (1991) to calculate the confidence interval (CI) for each gender group [31]. We used time to any of three events; death, cholangiocarcinoma, or liver transplant, as a response variable and used the Cox proportional hazards model to investigate what factors had a statistically significant effect on hazard rates. Two-sided Fisher's exact test and Pearson's exact test were used to compare proportions and crude incidence rates, respectively. Wilcoxon-Mann-Whitney test was used to compare continuous variables. All analyses were two-tailed and a p-value of $<0.05$ was considered as statistically significant.

\section{Results}

\section{Patient Characteristics}

We identified 169 patients who fulfilled the diagnostic criteria for PSC during the study period (Table 1). Of these 101 (59.8\%) were males. The mean age at diagnosis was 44 years (range 11-81). There were 12 (7\%) cases diagnosed before the age of 18 years. Age groups at diagnosis in adult cases included $49(30 \%)$ at ages 18-35 years, $82(50 \%)$ at ages $36-65$ years, and $21(13 \%)$ at ages $>65$ years. Five $(3 \%)$ cases were considered to have small duct PSC based upon a normal appearing cholangiogram and liver histology consistent with PSC.

IBD was present in 109 (64.5\%) PSC cases and was classified as UC in 95, CD in 13, and indeterminate colitis in one case. Patients with PSC and IBD were significantly younger with a mean ( \pm standard deviation) age of $41.1 \pm$ 1.6 years compared to $49.4 \pm 2.4$ years in PSC cases without IBD $(P=0.005)$. A significant difference in the frequency of IBD by gender was observed with IBD diagnosed significantly more frequently in men compared to women $(73.3 \%$ and $51.5 \%$, respectively, $\mathrm{P}=0.005)$. No 
Table 1 Demographic, biochemical, and clinical characteristics of 169 PSC cases diagnosed within a northern Californian HMO in the 2000-2006 period

\begin{tabular}{|c|c|c|}
\hline Age at diagnosis, years & $44.2 \pm 17.4$ & $(11-81)$ \\
\hline Males, $n(\%)$ & $101(59.8)$ & \\
\hline \multicolumn{3}{|l|}{ Ethnicity,n (\%) } \\
\hline White & $51(30.2)$ & \\
\hline African American & $15(8.9)$ & \\
\hline Hispanic & $9(5.3)$ & \\
\hline Asian/Pacific Islander & $3(1.8)$ & \\
\hline Other/Unknown & $91(53.8)$ & \\
\hline \multicolumn{3}{|l|}{ Laboratory Values at Diagnosis } \\
\hline Alkaline Phosphatase, IU/L & $283.4 \pm 256.8$ & $(30-1355)$ \\
\hline Aspartate Aminotransferase, IU/L & $66 \pm 65.7$ & $(13-407)$ \\
\hline Alanine Aminotransferase, IU/L & $70.3 \pm 71.9$ & $(11-339)$ \\
\hline Total bilirubin, $g / d L$ & $2.3 \pm 3.7$ & $(0.2-19.7)$ \\
\hline Serum albumin, $g / d L$ & $3.8 \pm 0.8$ & $(1.3-5.1)$ \\
\hline International Normalized Ratio & $1.1 \pm 0.2$ & $(0.9-2.7)$ \\
\hline MELD & $9.6+4.1$ & $(6.4-27.4)$ \\
\hline $\mathrm{IBD}, n(\%)$ & $109(64.5)$ & \\
\hline Ulcerative colitis & $95(56.2 \%)$ & \\
\hline Crohn's disease & $13(7.7 \%)$ & \\
\hline Indeterminate colitis & $1(0.6 \%)$ & \\
\hline \multicolumn{3}{|l|}{ Outcomes, $n$} \\
\hline Liver Transplantation & 23 & \\
\hline Cholangiocarcinoma & 7 & \\
\hline Death & 25 & \\
\hline
\end{tabular}

All continuous variables are expressed as mean \pm standard deviation (range).

significant differences in age at diagnosis were observed between genders.

\section{Prevalence and Incidence}

In December 2005 there were 140 cases of PSC alive and included in the database. The KP membership at this time consisted of 3,236,094 members giving an overall age-adjusted prevalence of 4.03 per 100,000 (95\% CI 3.36 - 4.70). Gender specific age-adjusted prevalence was 4.92 (95\% CI 3.86 - 5.97) and 3.19 (95\% CI 2.36 4.02) for men and women, respectively.

Eighty-one of the 169 cases were incident between January 2000 and October 2006. The overall ageadjusted PSC incidence was 0.41 (95\% CI 0.32 to 0.51 ) per 100,000 person-years. Stratified by gender, the ageadjusted incidence rate for males was numerically greater than females $(0.45$ (95\% CI $0.33-0.61)$ and 0.37 (95\% CI 0.26 - 0.51) per 100,000 person-years, respectively). Figure 1 illustrates the adjusted incidence rates by age groups and gender.

\section{Outcomes}

Twenty-three (13\%) PSC cases underwent liver transplantation, 9 of which were performed during the study period. Seven (4\%) PSC cases were diagnosed with

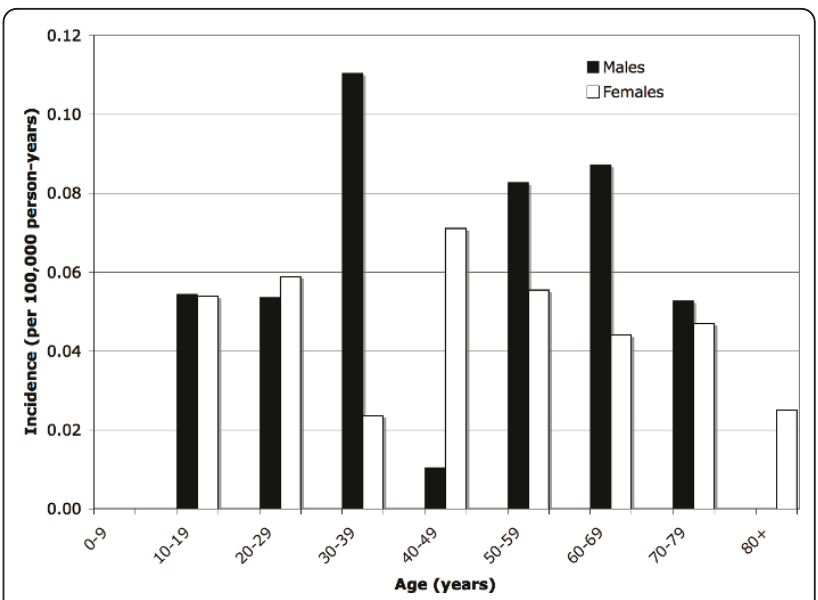

Figure 1 Adjusted Incidence Rates of Primary Sclerosing Cholangitis in Northern California by Age and Gender, 20002006.

cholangiocarcinoma and 25 (13\%) deaths occurred during the study period with 16 being liver-related (Table 2). Regression analyses based on the Cox proportional hazards model demonstrated that age at diagnosis $(\mathrm{p}=$ $0.02)$, serum sodium at diagnosis $(\mathrm{p}=0.02)$, creatinine at diagnosis $(\mathrm{p}=0.03)$, bilirubin at diagnosis $(\mathrm{p}=0.003)$, albumin at diagnosis $(\mathrm{p}=0.004)$, and albumin at last entry $(p=0.005)$ were statistically significant factors associated with death, liver transplantation or cholangiocarcinoma (Table 3). More specifically, the hazard rate was significantly increased with the increase of age at diagnosis, sodium at diagnosis and creatinine at diagnosis and significantly decreased with the increase of albumin at diagnosis and the increase of albumin at last entry. Race (White versus non-White) was not a significant factor in this analysis.

Table 2 Cause of death in PSC patients from 2000-2006

\begin{tabular}{lll}
\hline Cause & Number of Deaths \\
\hline Liver-related & & 7 \\
& Liver failure & 4 \\
& Hepatorenal syndrome & 3 \\
& Cholangiocarcinoma & 1 \\
& Liver Cancer, unspecified & 1 \\
& Cholangitis/Sepsis & 1 \\
\hline
\end{tabular}

Non Liver-related

$\begin{array}{ll}\text { Colon Cancer } & 2 \\ \text { Myocardial infarction } & 2 \\ \text { Squamous Cell Cancer } & 1 \\ \text { Pulmonary fibrosis } & 1 \\ \text { Pulmonary embolism } & 1 \\ \text { Urosepsis } & 1 \\ \text { Unknown } & 1\end{array}$


Table 3 Univariate Analysis of Proportional Hazards Regression to Death, Cholangiocarcinoma or Liver Transplant

\begin{tabular}{|c|c|c|c|}
\hline Characteristic & Hazard ratio (HR) & 95\% HR confidence interval & P-value \\
\hline Gender & 1.065 & $(0.515,2.200)$ & 0.87 \\
\hline Race & 0.835 & $(0.3,2.327)$ & 0.73 \\
\hline \multicolumn{4}{|l|}{ White } \\
\hline \multicolumn{4}{|l|}{ Non-white } \\
\hline Age at diagnosis & 1.029 & $(1.004,1.054)$ & 0.02 \\
\hline IBD & 0.657 & $(0.315,1.373)$ & 0.26 \\
\hline \multicolumn{4}{|l|}{ No } \\
\hline \multicolumn{4}{|l|}{ Yes } \\
\hline \multicolumn{4}{|l|}{ Lab measurement at study entry } \\
\hline Sodium & 1.144 & $(1.022,1.28)$ & 0.02 \\
\hline Creatinine & 4.034 & $(1.116,14.584)$ & 0.03 \\
\hline Alkaline phosphatase & 1.000 & $(0.999,1.002)$ & 0.47 \\
\hline Alanine aminotransferase & 0.997 & $(0.993,1.001)$ & 0.14 \\
\hline Aspartate aminotransferase & 0.996 & $(0.992,1.001)$ & 0.13 \\
\hline Bilirubin & 1.122 & $(1.039,1.211)$ & 0.003 \\
\hline INR & 1.569 & $(0.874,2.818)$ & 0.13 \\
\hline Albumin & 1.013 & $(0.938,1.095)$ & 0.74 \\
\hline MELD & 1.066 & $(0.998,1.139)$ & 0.06 \\
\hline \multicolumn{4}{|l|}{ Lab measurement at last entry } \\
\hline Sodium & 0.941 & $(0.804,1.101)$ & 0.45 \\
\hline Creatinine & 1.873 & $(0.711,4.932)$ & 0.20 \\
\hline Alkaline phosphatase & 1.001 & $(0.999,1.003)$ & 0.51 \\
\hline Alanine aminotransferase & 0.999 & $(0.992,1.006)$ & 0.76 \\
\hline Aspartate aminotransferase & 1.000 & $(0.994,1.006)$ & 0.99 \\
\hline Bilirubin & 1.09 & $(0.982,1.210)$ & 0.11 \\
\hline International normalized ratio & 1.335 & $(0.440,4.045)$ & 0.61 \\
\hline Albumin & 0.329 & $(0.153,0.709)$ & 0.005 \\
\hline
\end{tabular}

\section{Discussion}

The results of our study, which to our knowledge is the largest population-based case-finding study on PSC, demonstrate a prevalence of 4.03 cases per 100,000 and an incidence of 0.41 per 100,000 person-years. Similar to other populations, the majority of cases are males and IBD, particularly UC, is associated with PSC and is more frequent in males compared to females. We also identified several variables associated with the major disease outcomes, i.e. death, liver transplantation and cholangiocarcinoma.

PSC is a rare cholestatic disorder of unknown etiology for which there is no effective therapy. Although the prevalence of the disease appears to vary widely in different ethnic and racial groups, most population-based studies of PSC have been in relatively homogeneous populations in terms of ethnic and racial composition [13-17]. We sought to determine the prevalence and incidence of PSC in an ethnically and racially diverse population. The Northern California region is comprised of many different ethnic and racial groups with non-Hispanic whites making up only a slight majority of $51.1 \%$ based on 2000 US Census data. Because a strong association between PSC and IBD has always been observed to a lesser or greater degree and the risk of IBD varies between ethnic and racial groups, the prevalence of PSC might be similarly affected. Alternatively, the genetic basis of PSC appears to be independent of IBD genetic risk factors suggesting that there may not be a strict correlation between rates of IBD and PSC [9,32].

Similar to other PSC cohorts, we observed a predominance of males with a mean age at diagnosis in the midforties. The frequency of IBD was similar to other studies and we identified a significantly lower frequency of IBD in women with PSC, which is consistent with the findings of other smaller studies $[33,34]$. These rates should be 
considered a lower limit of the actual frequency. Some subjects did not have a record of a colonoscopy and often times the IBD of PSC is asymptomatic $[3,35,36]$. Whether the gender differences we observed are due to differences in true IBD prevalence or in rates of diagnosis warrant further investigation.

One of the most striking differences in our study compared to prior studies is the lower incidence and prevalence of PSC in this population compared to populations of Olmstead County, Alberta, Wales and Norway. This would seem to contradict the assertion by some authors that there is an increasing incidence of PSC diagnoses since the widespread use of endoscopic retrograde cholangiography and magnetic resonance cholangiography was introduced. One possible explanation for this discrepancy could be the result of under diagnosis leading to an underestimation of the true disease prevalence. PSC is a rare disease that may not be recognized by a clinician without particular skills or awareness. In addition, because there is not an effective therapy for PSC and liver test abnormalities are frequent in IBD, some clinicians may prefer not to confirm the diagnosis of PSC when it is suspected, particularly if an invasive test is needed. It is notable that our estimates of PSC prevalence and incidence are similar to those of another recent large study of a subset of the British population (total population of $2,027,909$ ), which like the present study, was not based on one or a few hospitals with a particular interest in PSC [17].

Alternatively, this discrepancy might be due to a lower incidence of IBD, particularly UC, within Northern California. However, a recent study of the KP database determined that the incidence and prevalence of $\mathrm{UC}$ and $\mathrm{CD}$ is similar to or greater than that of Olmstead County, Manitoba and Europe [37]. Nevertheless, differences in the ethnic distribution between IBD and the total population have been noted[37,38]. A prior study of a subset of this population in Oakland, CA reported that non-Hispanic whites made up only $64 \%$ of the total population but represented $80 \%$ of the IBD cases [38]. In contrast, Hispanics and Asian Americans comprised a disproportionately smaller percentage of the IBD cases compared to the total membership. In the more recent study of the total KP population, African Americans and Asians constituted $16 \%$ and $9 \%$ of the total IBD population, respectively, compared to $6 \%$ and $16 \%$ of the membership[37]. Further, other studies suggested that PSC is rare in Asia and that African Americans are at greater risk of developing extra-intestinal manifestation of IBD, including PSC $[23,24,26-28]$. Ethnicity was documented in the medical record in fewer than half of the cases preventing us from drawing conclusions about the effect of ethnicity on the prevalence or incidence of PSC.

The strengths of our study include the use of comprehensive paper and electronic medical records to ascertain details of the PSC cases, the representative population of the northern California KP and the community care setting as opposed to a tertiary referral center. In contrast to the UK study, we were able to confirm each case of PSC based upon accepted diagnostic criteria. In addition, the size of the population allowed us to more accurately estimate the incidence and prevalence of a relatively rare disease. Therefore, these results are likely to be more representative of the total population.

Our study did have some weaknesses. The lack of ethnic and racial data in a large subset of patients limited our ability to address risk assessment or determination of prognostic factors for the natural course of disease dependent on race. We also note that not all patients with PSC had colonoscopies and therefore our estimates of IBD are likely underestimates of the actual rates. Finally, although this population is generally representative of the total population of Northern California, there is some skewing away from the upper and lower income groups.

\section{Conclusions}

We have reported on the largest population based study of PSC to date and the only one to include an ethnically diverse population. Although the common features of age at diagnosis, male predominance and presence of IBD are similar to other studies, we observed lower PSC prevalence and incidence rates than reported in most other populations. Further studies in this or other similar populations will be helpful in determining if there are significant differences in PSC susceptibility and clinical outcomes between ethnic groups.

\section{Abbreviations}

PSC: primary sclerosing cholangitis; IBD: inflammatory bowel disease; KP: Kaiser Permanente; UC: ulcerative colitis; Cl: confidence interval.

\section{Acknowledgements}

Funding: Statistical support was made possible by Grant Number UL1 RR024146 from the National Center for Research Resources (NCRR), a component of the National Institutes of Health $(\mathrm{NIH})$, and $\mathrm{NIH}$ Roadmap for Medical Research. Its contents are solely the responsibility of the authors and do not necessarily represent the official view of NCRR or $\mathrm{NIH}$. Information on Reengineering the Clinical Research Enterprise can be obtained from http://nihroadmap.nih.gov/clinicalresearch/overviewtranslational.asp.

\section{Author details}

'Department of Medicine, University of California Davis Medical Center, Sacramento, CA USA. ²Division of Gastroenterology, Kaiser Permanente Medical Group, Sacramento, CA USA. ${ }^{3}$ Autoimmunity and Metabolism Unit, IRCCS Istituto Clinico Humanitas, Rozzano, Milan, Italy. ${ }^{4}$ Division of Rheumatology, Allergy and Clinical Immunology, University of California Davis, Davis, CA USA. ${ }^{5}$ Department of Public Health Sciences, Division of Biostatistics, University of California Davis, Davis, CA USA. ${ }^{6}$ Division of Gastroenterology and Hepatology, University of California Davis Medical Center, Sacramento, CA USA.

\section{Authors' contributions}

ET participated in the study design, data abstraction and analysis and assisted with the drafting of the manuscript. SB and CS participated in the 
study design and data analysis. CSL participated in the data analysis. CLB conceived of the study and participated in its design and coordination and drafting of the manuscript. All authors read and approved the final manuscript.

\section{Competing interests}

The authors declare that they have no competing interests.

Received: 19 April 2011 Accepted: 18 July 2011 Published: 18 July 2011

\section{References}

1. Aoki CA, Bowlus $\mathrm{CL}$, Gershwin ME: The immunobiology of primary sclerosing cholangitis. Autoimmun Rev 2005, 4(3):137-143.

2. EASL Clinical Practice Guidelines: management of cholestatic liver diseases. J Hepatol 2009, 51(2):237-267.

3. Faubion WA Jr, Loftus EV, Sandborn WJ, Freese DK, Perrault J: Pediatric "PSC-IBD": a descriptive report of associated inflammatory bowel disease among pediatric patients with psc. J Pediatr Gastroenterol Nutr 2001, 33(3):296-300.

4. Loftus EV Jr, Harewood GC, Loftus CG, Tremaine WJ, Harmsen WS, Zinsmeister AR, Jewell DA, Sandborn WJ: PSC-IBD: a unique form of inflammatory bowel disease associated with primary sclerosing cholangitis. Gut 2005, 54(1):91-96.

5. Loftus EV Jr, Sandborn WJ, Tremaine WJ, Mahoney DW, Zinsmeister AR, Offord KP, Melton L: Primary sclerosing cholangitis is associated with nonsmoking: a case-control study. Gastroenterology 1996, 110(5):1496-1502.

6. Mitchell SA, Thyssen M, Orchard TR, Jewell DP, Fleming KA, Chapman RW: Cigarette smoking, appendectomy, and tonsillectomy as risk factors for the development of primary sclerosing cholangitis: a case control study. Gut 2002, 51(4):567-573.

7. van Erpecum KJ, Smits SJ, van de Meeberg PC, Linn FH, Wolfhagen FH, vanBerge-Henegouwen GP, Algra A: Risk of primary sclerosing cholangitis is associated with nonsmoking behavior. Gastroenterology 1996, 110(5):1503-1506.

8. Spurkland A, Saarinen S, Boberg KM, Mitchell S, Broome U, Caballeria L, Ciusani E, Chapman R, Ercilla G, Fausa O, et al: HLA class II haplotypes in primary sclerosing cholangitis patients from five European populations. Tissue Antigens 1999, 53(5):459-469.

9. Karlsen TH, Boberg KM, Vatn M, Bergquist A, Hampe J, Schrumpf E, Thorsby E, Schreiber S, Lie BA: Different HLA class II associations in ulcerative colitis patients with and without primary sclerosing cholangitis. Genes Immun 2007, 8(3):275-278.

10. Bittencourt PL, Palacios SA, Cancado EL, Carrilho FJ, Porta G, Kalil J, Goldberg AC: Susceptibility to primary sclerosing cholangitis in Brazil is associated with HLA-DRB1*13 but not with tumour necrosis factor alpha -308 promoter polymorphism. Gut 2002, 51(4):609-610.

11. Neri TM, Cavestro GM, Seghini P, Zanelli PF, Zanetti A, Savi M, Podda M, Zuin $M$, Colombo M, Floreani A, et al: Novel association of HLAhaplotypes with primary sclerosing cholangitis (PSC) in a southern European population. Dig Liver Dis 2003, 35(8):571-576.

12. Bowlus $C L, L i C S$, Karlsen TH, Lie BA, Selmi C: Primary sclerosing cholangitis in genetically diverse populations listed for liver transplantation: Unique clinical and HLA associations. Liver Transplantation 2010

13. Bambha K, Kim WR, Talwalkar J, Torgerson H, Benson JT, Therneau TM, Loftus EV Jr, Yawn BP, Dickson ER, Melton LJ: Incidence, clinical spectrum, and outcomes of primary sclerosing cholangitis in a United States community. Gastroenterology 2003, 125(5):1364-1369.

14. Boberg KM, Aadland E, Jahnsen J, Raknerud N, Stiris M, Bell H: Incidence and prevalence of primary biliary cirrhosis, primary sclerosing cholangitis, and autoimmune hepatitis in a Norwegian population. Scand J Gastroenterol 1998, 33(1):99-103.

15. Kaplan GG, Laupland KB, Butzner D, Urbanski SJ, Lee SS: The burden of large and small duct primary sclerosing cholangitis in adults and children: a population-based analysis. Am J Gastroenterol 2007, 102(5):1042-1049.

16. Kingham JG, Kochar N, Gravenor MB: Incidence, clinical patterns, and outcomes of primary sclerosing cholangitis in South Wales, United Kingdom. Gastroenterology 2004, 126(7):1929-1930.
17. Card TR, Solaymani-Dodaran M, West J: Incidence and mortality of primary sclerosing cholangitis in the UK: a population-based cohort study. J Hepatol 2008, 48(6):939-944.

18. Lindkvist B, Benito de Valle M, Gullberg B, Bjornsson E: Incidence and prevalence of primary sclerosing cholangitis in a defined adult population in Sweden. Hepatology 2010, 52(2):571-577.

19. Ang TL, Fock KM, Ng TM, Teo EK, Chua TS, Tan JY: Clinical profile of primary sclerosing cholangitis in Singapore. J Gastroenterol Hepatol 2002. 17(8):908-913.

20. Okolicsanyi L, Fabris L, Viaggi S, Carulli N, Podda M, Ricci G: Primary sclerosing cholangitis: clinical presentation, natural history and prognostic variables: an Italian multicentre study. The Italian PSC Study Group. Eur J Gastroenterol Hepatol 1996, 8(7):685-691

21. Escorsell A, Pares A, Rodes J, Solis-Herruzo JA, Miras M, de la Morena E: Epidemiology of primary sclerosing cholangitis in Spain. Spanish Association for the Study of the Liver. J Hepatol 1994, 21(5):787-791.

22. Hurlburt KJ, McMahon BJ, Deubner H, Hsu-Trawinski B, Williams JL, Kowdley KV: Prevalence of autoimmune liver disease in Alaska Natives. Am J Gastroenterol 2002, 97(9):2402-2407.

23. Kochhar R, Goenka MK, Das K, Nagi B, Bhasin DK, Chawla YK, Vaiphei K, Singh K, Dilawari JB: Primary sclerosing cholangitis: an experience from India. J Gastroenterol Hepatol 1996, 11(5):429-433.

24. Takikawa H, Takamori Y, Tanaka A, Kurihara H, Nakanuma Y: Analysis of 388 cases of primary sclerosing cholangitis in Japan; Presence of a subgroup without pancreatic involvement in older patients. Hepatol Res 2004, 29(3):153-159.

25. Kamisawa T, Egawa N, Tsuruta K, Okamoto A, Funata N: Primary sclerosing cholangitis may be overestimated in Japan. J Gastroenterol 2005, 40(3):318-319.

26. Kelly P, Patchett S, McCloskey D, Alstead E, Farthing M, Fairclough P: Sclerosing cholangitis, race and sex. Gut 1997, 41(5):688-689.

27. Simsek H, Schuman BM: Inflammatory bowel disease in 64 black patients: analysis of course, complications, and surgery. J Clin Gastroenterol 1989, 11(3):294-298.

28. Nguyen GC, Torres EA, Regueiro M, Bromfield G, Bitton A, Stempak J, Dassopoulos T, Schumm P, Gregory FJ, Griffiths AM, et al: Inflammatory bowel disease characteristics among African Americans, Hispanics, and non-Hispanic Whites: characterization of a large North American cohort. Am J Gastroenterol 2006, 101(5):1012-1023.

29. Krieger N: Overcoming the absence of socioeconomic data in medical records: validation and application of a census-based methodology. Am J Public Health 1992, 82(5):703-710.

30. Weng X, Liu L, Barcellos LF, Allison JE, Herrinton LJ: Clustering of inflammatory bowel disease with immune mediated diseases among members of a northern california-managed care organization. Am J Gastroenterol 2007, 102(7):1429-1435.

31. Dobson AJ, Kuulasmaa K, Eberle E, Scherer J: Confidence intervals for weighted sums of Poisson parameters. Stat Med 1991, 10(3):457-462.

32. Karlsen TH, Hampe J, Wiencke K, Schrumpf E, Thorsby E, Lie BA, Broome U, Schreiber S, Boberg KM: Genetic polymorphisms associated with inflammatory bowel disease do not confer risk for primary sclerosing cholangitis. Am J Gastroenterol 2007, 102(1):115-121.

33. Rabinovitz M, Gavaler JS, Schade RR, Dindzans VJ, Chien MC, Van Thiel DH: Does primary sclerosing cholangitis occurring in association with inflammatory bowel disease differ from that occurring in the absence of inflammatory bowel disease? A study of sixty-six subjects. Hepatology 1990, 11(1):7-11.

34. Olsson $R$, Danielsson $A$, Jarnerot $G$, Lindstrom $E$, Loof $L$, Rolny $P$, Ryden $B O$, Tysk C, Wallerstedt S: Prevalence of primary sclerosing cholangitis in patients with ulcerative colitis. Gastroenterology 1991, 100(5 Pt 1):1319-1323.

35. Lundqvist $\mathrm{K}$, Broome $\mathrm{U}$ : Differences in colonic disease activity in patients with ulcerative colitis with and without primary sclerosing cholangitis: a case control study. Dis Colon Rectum 1997, 40(4):451-456.

36. Moayyeri A, Daryani NE, Bahrami H, Haghpanah B, Nayyer-Habibi A, Sadatsafavi M: Clinical course of ulcerative colitis in patients with and without primary sclerosing cholangitis. J Gastroenterol Hepatol 2005, 20(3):366-370.

37. Herrinton $L$, Liu L, Lewis JD, Griffin PM, Allison J: Incidence and prevalence of inflammatory bowel disease in a Northern California 
managed care organization, 1996-2002. Am J Gastroenterol 2008, 103(8):1998-2006.

38. Hiatt RA, Kaufman L: Epidemiology of inflammatory bowel disease in a defined northern California population. West J Med 1988, 149(5):541-546.

Pre-publication history

The pre-publication history for this paper can be accessed here: http://www.biomedcentral.com/1471-230X/11/83/prepub

doi:10.1186/1471-230X-11-83

Cite this article as: Toy et al:: The prevalence, incidence and natural history of primary sclerosing cholangitis in an ethnically diverse population. BMC Gastroenterology 2011 11:83.

Submit your next manuscript to BioMed Central and take full advantage of:

- Convenient online submission

- Thorough peer review

- No space constraints or color figure charges

- Immediate publication on acceptance

- Inclusion in PubMed, CAS, Scopus and Google Scholar

- Research which is freely available for redistribution

Submit your manuscript at www.biomedcentral.com/submit 